hybrid, and this factor is probably intimately associated with the colour of the crystals.

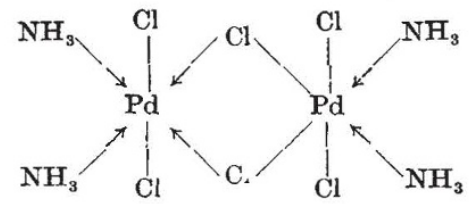

Dr. Dwyer's paper contains many interesting points. It is particularly noteworthy that the tris-diazoaminobenzene-palladium readily lost a molecule of diazoaminobenzene, and that the bis. diazoaminobenzene-palladium so formed could not be converted back to the original tris-derivative. This is not unexpected. The bis-derivative, having undoubtedly the planar configuration, could not undergo simple union with a third molecule of diazoaminobenzene, since the latter molecule would be unable to span the $1: 6$ position of the potential hexacovalent octahedron. The union would therefore be a complex process leading to an unstable compound, and hence does not apparently occur. I have discussed other cases of this phenomenon elsewhere ${ }^{6}$.

University Chemical Laboratory,

$$
\text { F. G. MANN. }
$$
Cambridge.

' Nature, 147, 612 (1941).

${ }^{2} J$. Amer. Chem. Soc., 63, 78 (1941).

3 J. Chem. Soc., 892 (1928); 654 (1929).

- Drew, Pinkard, Preston and Wardlaw, J. Chem. Sor., 1898 (1.732).

s Mann and Purdie, J. Chem. Soc., 881 (1936).

'J. Chem. Soc., 412 (1933).

\section{Textures of Clays}

Probably the best method of evaluating the texture of a clay is to slake it up with water or break it up into its component parts by some method such as alternate drying and slaking, and then to size by combined sieve and pipette or hydrometer analyses. If this in turn is combined with microscopic examination, the grain shapes can be determined and an accurate conception can be obtained of the grain size distribution. The more detailed this size analysis the more valuable it is. However, without the mineralogical composition, the picture of the structure and texture is very incomplete. To quote an extreme case, a kaolin consisting of particles 95 per cent less than 43 microns and the main mineral being kaolinite, may be only slightly plastic, whereas another clay having about 50 per cent of its particles less than 43 microns in diameter but containing waterswelling minerals of the montmorillonite group may be very plastic and have a very high modulus of rupture as well.

To take two examples, the mechanical analyses were as follows :

\begin{tabular}{|c|c|c|}
\hline & 1 & 2 \\
\hline Coarse sand & $4 \cdot 30$ & nil \\
\hline Fine sand & $24 \cdot 80$ & $1 \cdot 23$ \\
\hline Silt & $35 \cdot 60$ & $37 \cdot 90$ \\
\hline Clay & $28 \cdot 80$ & $61 \cdot 12$ \\
\hline \multirow[t]{2}{*}{ Moisture } & $3 \cdot 57$ & 0.05 \\
\hline & 97.07 & $100 \cdot 30$ \\
\hline
\end{tabular}

At first glance one would be inclined to say that the second specimen would be the more plastic.
Actually the kaolin is practically non-plastic although it is not hard and compact. The first sample contains some vermicular kaolinite, but is mainly composed of ferruginous clay minerals and illite. The second is composed almost wholely of kaolinite with some quartz. The kaolinite is platey and there is a high degree of coarse crystallinity. The first elay has a modulus of rupture of $390 \mathrm{lb} . / \mathrm{sq}$. in., whereas the value for the kaolin is less than $10 \mathrm{lb} . / \mathrm{sq}$. in.

Actually this type of analysis is not discriminating enough, and in later work the conventional size separates used by soil seientists was abandoned. The sub-sieve sizes were then dealt with in the following manner :- $43-31,31-16, \quad 16-11, \quad 11-5 \cdot 5, \quad 5 \cdot 5-2 \cdot 0$, $2 \cdot 0-1 \cdot 0$ microns, or as the texture of the clay varied. The method is flexible and the ultimate aim is to get the size distribution of the elay, rather than to fit the clay to a conventional nomenclature. If it is desired to compare the size distribution of two or more clays this can be best done graphically.

A problem that has not been solved is the condition of the organic phases ${ }^{1}$. The organic compounds are, with the exception of grass roots, etc., always associated with the finest sizes. That plasticity, green strength and other physical properties are influenced by the presence or absence of the peaty substances present in certain fireclays, kaolins and bog clays is evident from an examination of such rocks. In the case of a certain sedimentary kaolin, certain phases of the same clay contained organic matter and others did not. The difference in plasticity was striking.

$$
\begin{aligned}
& \text { University of the Witwatersrand, } \\
& \text { Johannesburg. } \\
& { }^{1} \text { Bosazza, V. L., NArURe, 144, } 835 \text { (1939). }
\end{aligned}
$$

\section{L. Bosazz.A.}

\section{Sense of Hearing in Fishes}

I AM sure that the fish described in Dr. C. B. Williams' communication ${ }^{1}$ did hear the bicycle bell, as a disturbance of the norm to which it is 'conditioned'. Dr. Bull has had to make a sound-proof room for his experiments at Cullercoats on the behaviour of blennies, etc. ${ }^{2}$

But the simplicity of the inner ear of fish, in which there is only an otolith floating in a saccule to serve instead of the graded tuning-forks of the mammalian cochlea, allows us to expect most fish to be rather hard of hearing, except in examples where we know to the contrary. The degree of hearing must vary from species to species, because the acoustic region of the brain shows varying degrees of development, even within one family ; and some fish have.well-developed 'aids to the deaf' made from part of the swim bladder, for example, in carp and herring. All this, and more, is to be found in Dr. H. Muir Evans's recent book ${ }^{3}$. Dr. Evans's researches show that fishes have more elaborate organs of reception and perception than the text-books have led us to suppose. Sight, hearing and taste may all be well developed, and in varying degrees, and in a few species there is a genuine under-water voice.

Fisheries Laboratory,

Michael Graham. Lowestoft.

$$
\text { May } 9 .
$$

1 NATURE, 147, 543 (1941).

${ }^{2}$ Dove Rep. (1934).

" "The Brain and Body of Fish" (Technical Press, 1940) 